\title{
OS MATERIAIS DIDÁTICOS COMO RECURSOS FUNDAMENTAIS DE POTENCIALIZAÇÃO DA QUALIDADE DO ENSINO E APRENDIZAGEM NA EAD
}

\author{
Michele Antunes Corrêa ${ }^{1}$
}

\section{RESUMO}

O propósito deste artigo é demonstrar, por meio da análise de referenciais teóricos da área, a importância dos materiais didáticos para a potencialização do ensino e da aprendizagem na Educação a Distância (EaD). Para tanto, verificou-se que os materiais elaborados para cursos nessa modalidade necessitam ser desenvolvidos de acordo com a concepção de educação a distância da instituição e devem ser constantemente avaliados, revisados e atualizados de acordo com os avanços e descobertas na área de conhecimento que tratam, possibilitando ensino e aprendizagem de qualidade. Pois se compreende que, na educação a distância, o material didático tem papel fundamental, uma vez que comporta a organização, o desenvolvimento e a dinâmica de todo o processo de ensino e aprendizagem, além de prever grande parte das estratégias didático-pedagógicas.

Palavras-chave: Educação a distância. Material didático. Ensino e aprendizagem.

${ }^{1}$ Especialista e-mail: michele.aacc@gmail.com 


\section{INTRODUÇÃO}

O crescimento em grande escala da oferta de educação a distância no Brasil e no mundo inteiro não é mais novidade. Dados referentes ao crescente número de instituições que oferecem cursos de educação a distância em diferentes modelos que relatam o salto no número de disciplinas e cursos ofertados, de alunos matriculados, de professores que desenvolvem conteúdos e atuam como professores tutores, a quantidade de pesquisas e publicações na área, e o grande número de tecnologias disponíveis e aplicáveis aos materiais didáticos e ao desenvolvimento das interações para a educação a distância, já fazem parte do nosso atual contexto educacional.

No entanto, o olhar quantitativo sobre a Educação a Distância (EaD) que nos é apresentado a todo momento, vem instigar e motivar o necessário olhar sobre a qualidade do ensino e aprendizagem que se espera e se busca encontrar no crescente número de cursos ofertados nessa modalidade.

Contudo, voltar-se para a qualidade do ensinar e aprender na EaD pode abranger diferentes elementos que estruturam e compõem o projeto de um curso nessa modalidade. Sendo assim, optou-se em lançar o olhar sobre os materiais didáticos, por compreender a importância destes, em suas diferentes formas, para o desenvolvimento e aprimoramento dos processos de ensino e aprendizagem na EaD. Partindo da análise de referenciais teóricos da área, busca-se responder alguns questionamentos relacionados aos materiais didáticos desenvolvidos para cursos na modalidade a distância. Com o objetivo de salientar a importância da avaliação desses materiais, como forma de potencializar a qualidade do ensino e aprendizagem na EaD.

Portanto, é atentando o olhar sobre a qualidade dos materiais didáticos que este artigo se lança, e busca contribuir para a área educacional, por compreender que os materiais didáticos para o ensino a distância possuem dinâmica e características diferenciadas do ensino presencial.

\section{QUALIDADE NA EAD}

Conforme documentos legais e referenciais para a educação a distância, a base legal da EaD no Brasil foi regulada pela Lei de Diretrizes e Bases da Educação Brasileira (LDB - Lei $n^{\circ}$ 9.394/96) que estabelece, em seu artigo 80, a possibilidade de uso orgânico da modalidade de educação a distância em todos os níveis e modalidades de ensino (BRASIL ,1996).

Legalizada a oferta de EaD, o crescimento do número de instituições que passam a oferecer cursos na modalidade a distância reflete as necessidades e demandas da atual sociedade, que se caracteriza pelo desenvolvimento acelerado e por constantes 
inovações tecnológicas. Assim, a busca por conhecimento torna-se cada vez mais necessária, e as Tecnologias da Informação e Comunicação (TICs) vêm conquistando espaço e se fazendo indispensáveis no sistema educacional. Portanto, nesse contexto, a educação a distância se expande se adapta e adapta diferentes tecnologias e formas de ensino e aprendizagem para atender essa nova realidade.

Com essa grande demanda em EaD surge a preocupação com a qualidade e as seguintes perguntas se fazem necessárias: "Com base em quais referenciais estão sendo desenvolvidos esse grande número de cursos?"; "Existem padrões de qualidade?".

Em complemento às determinações específicas da LDB foi elaborado, em 2003, pela Secretaria de Educação a Distância (SEED) e pelo Ministério da Educação (MEC), os documentos Referenciais de Qualidade para Cursos a Distância, com o intuito de definir princípios, diretrizes e critérios que sejam referenciais de qualidade para as instituições que oferecem cursos nessa modalidade.

Embora não tenham força de lei, os Referenciais são norteadores para subsidiar atos legais do poder público no que se referem aos processos de supervisão, avaliação e regulação de cursos na modalidade a distância. Conforme os Referenciais:

Programas, cursos, disciplinas ou mesmo conteúdos oferecidos a distância exigem administração, desenho, lógica, linguagem, acompanhamento, avaliação, recursos técnicos, tecnológicos e pedagógicos, que não são mera transposição do presencial. Ou seja, a educação a distância tem sua identidade própria. (BRASIL, 2003, p.6).

Nesse sentido, esses Referenciais de Qualidade apontam para as concepções teóricometodológicas da educação a distância, como também, sobre todas as organizações que tenham a implementação de cursos em EaD, para que estejam condizentes com as especificidades da modalidade e de acordo com o modelo que adotam. Dessa forma, não existe um modelo único de $\mathrm{EaD}$, mas sim, diferentes modelos que se utilizam de diversificadas metodologias e tecnologias para atender a demanda e as especificidades do público-alvo e dos cursos oferecidos.

Portanto, os programas a distância podem apresentar diferentes desenhos e múltiplas combinações de linguagens e recursos educacionais e tecnológicos, respeitando sempre o fato de que não podem abrir mão da qualidade em todo o processo. (BRASIL, 2003, p.6).

Desta forma, buscou-se também, no documento Referenciais para Elaboração de Material Didático para EaD no Ensino Profissional e Tecnológico (BRASIL, 2007b), desenvolvido por especialistas da área, orientações específicas sobre concepção e desenvolvimento de materiais didáticos que servem para enfatizar a necessária importância que estes têm para o ensino e aprendizagem na EaD.

Cada programa, baseado na natureza dos cursos que disponibiliza, no nível de ensino que atende, no contexto e necessidade de seus alunos, pode apresentar diferentes 
desenhos, múltiplas combinações de linguagens e diversificados materiais e recursos educacionais e tecnológicos.

Com a crescente oferta de cursos e programas de EaD, aliada a essa diversidade de projetos e modelos, torna-se fundamental a avaliação e o estabelecimento de padrões mínimos de qualidade. Segundo os Referenciais, os projetos de cursos na modalidade a distância devem compreender categorias que envolvam recursos humanos, infraestrutura e aspectos pedagógicos. Sendo assim, para dar conta destas dimensões, os projetos de EaD devem contemplar alguns tópicos fundamentais:

(i) concepção de educação e currículo no processo de ensino e aprendizagem;

(ii) sistemas de comunicação;

(iii) material didático;

(iv) avaliação;

(v) equipe multidisciplinar;

(vi) infraestrutura de apoio;

(vii) gestão acadêmico-administrativa;

(viii) sustentabilidade financeira. (BRASIL, 2007a, p. 8).

Dentre os tópicos anteriormente citados, o objetivo aqui é a análise do item (iii), Material didático, considerando a sua importância para o ensino e aprendizagem na EaD, em seus diferentes formatos e mídias.

É importante enfatizar que a menção e breve análise neste artigo, dos Referenciais de Qualidade, se deve ao fato, destes terem sido elaborados com o intuito de garantir a qualidade dos processos, e nortear o desenvolvimento e manutenção da EaD.

\subsection{Ensino e aprendizagem na EAD}

Os processos de ensinar e aprender na $\mathrm{EaD}$, em grande parte, não ocorrem de forma simultânea, nem têm lugar em um espaço compartilhado por alunos e professores. Por tal motivo, as propostas de ensino nessa modalidade são mediatizadas por meio de materiais didáticos. Surge então a pergunta: "quais as especificidades do material didático para EaD?"

O material didático para a $\mathrm{EaD}$, diferentemente do ensino presencial, necessita ser autossuficiente, ou seja, deve ser produzido levando em consideração as características do processo de ensinar e aprender a distância. Conforme Sartori e Roesler (2005, p. 
65) "um material didático é autossuficiente quando apresenta, além do conteúdo e das avaliações, todas as orientações para que os alunos desenvolvam suas atividades de estudo, pesquisa, interações com colegas e professores."

Deste modo, as estratégias de ensino, assim como, todos os elementos que compõem o material didático devem estar finalizados para o início das atividades discentes, de modo que o aluno tenha à sua disposição tudo o que necessita para que seus estudos possam ser realizados de forma autônoma.

Na educação a distância, o material didático assume o papel de fio condutor, já que organiza o desenvolvimento e a dinâmica de todo o processo de ensino e aprendizagem.

O material didático para a $\mathrm{EaD}$, assim como os processos de ensino e aprendizagem que se estabelecem na relação do aluno com os conteúdos e do aluno com os colegas, professores e instituição, por meio das diferentes tecnologias, devem contemplar e estimular a autonomia, a interação e interatividade.

\subsubsection{Autonomia}

A autonomia na aprendizagem requer disciplina, decisão, organização, persistência, motivação, avaliação e responsabilidade. No que se refere à educação a distância, ser aluno autônomo é saber utilizar-se dos recursos tecnológicos que esta modalidade disponibiliza, adequando-os às reais necessidades individuais.

"Mas como os materiais didáticos podem contribuir para o estímulo da autonomia?"

$\mathrm{Na}$ EaD a autonomia não depende somente do aluno e de suas características individuais, depende também, dos materiais disponibilizados para sua autoaprendizagem, da metodologia, da interação com outros alunos, com o professor, da aplicação dos aprendizados em outros contextos, enfim, a autonomia do aluno requer não só aprendizagem, mas 'aprender a aprender'. De acordo com Vieira (1996 apud WISSMANN, 2006. p.3):

[...] essencialmente autonomia é a capacidade - para o desprendimento, reflexão crítica, tomada de decisões, e ação independente. Isto pressupõe, mas também requer que o aprendiz desenvolverá um tipo particular de psicologia relacionada ao processo e conteúdo de sua aprendizagem. A capacidade para a autonomia será demonstrada tanto pela maneira como o aprendiz aprende quanto pelo modo que ele/ela transfere o que tem sido aprendido para outros contextos.

Logo, ao produzir e desenvolver materiais para EaD deve-se levar em consideração que o material didático necessita ser de fácil interpretação, com linguagem adequada ao público que pretende atender, não podendo ser "fechado", ou seja, considerado como pronto e acabado, e sim, passível de adaptações e atualizações. Os mesmos devem permitir ao aluno estender seus conhecimentos para além do que está proposto, 
indicando, por exemplo, bibliografias complementares e atividades extras que auxiliem o aluno a continuar sua pesquisa e aprendizado de forma autônoma.

É importante que o material didático forneça explicações claras a respeito dos objetivos de cada unidade ou módulo do curso, sendo esse aspecto essencial para que o aluno possa ter a dimensão dos objetivos que deve desenvolver e atingir e possa organizar suas ações para alcançar estes objetivos. Sob esta perspectiva, o material didático exerce papel importante na autonomia do aluno, facilitando, incentivando e orientando.

Embora o termo autonomia enfatize a individualidade do aluno, no que diz respeito a necessidades, objetivos e capacidades - focando, desta maneira, na aprendizagem individual - segundo Wissmann (2006, p.3), a autonomia também é

[...] produto de um processo interativo definido pela essência interdependente de cada indivíduo como ser social que é. Deve-se reconhecer que a autonomia do aprendiz é muito mais um produto da interdependência do que da independência. Sendo assim, os aprendizes devem ser ajudados a adquirir autonomia por meio de um processo de interação semelhante à aprendizagem formal.

Nesse sentido, entende-se que o aluno de $\operatorname{EaD}$ (que, por exemplo, tenha acesso ao ambiente on-line de seu curso) desenvolva sua autonomia e independência e, de modo simultâneo, desenvolva a capacidade de participar de grupos e aprender em colaboração com seus colegas. Desta forma, a autonomia e a interação em EaD não devem ser consideradas conceitos excludentes, mas sim, práticas complementares e essenciais para o ensino e aprendizado dos alunos nesta modalidade.

\subsubsection{Interação e interatividade}

Os princípios de interação e interatividade encontram divergência entre diferentes grupos de autores sobre a equivalência ou diferenciação de seus significados. É importante ressaltar que, aqui, estes princípios serão considerados da seguinte forma: interação - como inerente ao seres humanos e ocorrendo quase sempre quando duas ou mais pessoas se comunicam. Já a interatividade está relacionada com as tecnologias de informação e comunicação, ocorrendo quando duas ou mais pessoas interagem, tendo como mediadora alguma interface tecnológica.

Assim sendo, ambos princípios (interação e interatividade) são de fundamental importância para o processo de comunicação e devem ser garantidos no uso de qualquer meio tecnológico a ser disponibilizado nos cursos de EaD. Ao considerar o estudante como centro do processo educacional, um dos pilares para garantir a qualidade de um curso a distância é a interação entre alunos, professores e demais agentes do processo de ensino e aprendizagem. Com o avanço das TIC, a interatividade também vem sendo cada vez mais explorada e facilitada. 
Portanto, em cursos a distância, o aluno deve estar no centro do processo educacional e a interação e a interatividade devem estar apoiadas entre outros pilares: em um adequado sistema de tutoria, em materiais de qualidade e no uso de diversificadas tecnologias, que devem ser especialmente implementadas para o atendimento às necessidades dos alunos. Como estratégia, o estímulo à interação e interatividade deve proporcionar a cooperação entre os alunos, propiciando a formação de grupos de estudos e comunidades de aprendizagem. Nesse sentido, afirma Kenski (2009, p.124-125) que:

Todos que vão elaborar cursos nas redes digitais devem ter consciência que professores e alunos são seres sociais e que aprendem melhor em um sistema cooperativo, baseado em trocas de informação e opiniões e no trabalho coletivo. Nessa forma mais avançada de ensino interativo, mediado pelas tecnologias digitais, a participação de todos é indispensável.

Neste contexto, os projetos de curso devem prever vias efetivas de comunicação e diálogo entre todos os agentes do processo educacional, criando condições para diminuir a sensação de isolamento e solidão, gerando assim, em seus alunos, a sensação de pertencimento e acolhimento. Desta forma, a educação a distância tem como um dos seus maiores desafios o desenvolvimento de materiais didáticos capazes de provocar e garantir a autonomia, a interação e a interatividade, necessárias para um ensino de qualidade.

Sendo assim, ao tratar de materiais didáticos para a EaD, torna-se essencial verificar as características que foram, ao longo do tempo, estruturando e configurando as diferentes gerações de EaD. Como também os tipos de sistemas de comunicação e tecnologias que impulsionaram o crescimento acelerado desta modalidade e trouxeram novas possibilidades e dimensões de tratamento dos materiais didáticos para a educação à distância.

\subsection{Material didático para EAD}

Historicamente, a educação a distância assumiu diferentes características e tornou-se uma modalidade de educação cada vez mais expansiva, principalmente pelo tratamento dado aos conteúdos nas diferentes formas de desenvolvimento dos materiais didáticos, proporcionadas pelos avanços dos meios tecnológicos. Como pode ser observado na descrição de Torres e Fialho (2009), a história da EaD no Brasil é marcada por cinco gerações que refletem as transformações na concepção e produção de materiais didáticos, devido aos avanços das tecnologias comunicacionais ao longo do tempo. São elas:

a) a primeira geração tinha como base metodológica o material didático impresso e o ensino por correspondência, os materiais eram autoexplicativos e utilizavam linguagem simplificada, essa geração teve seu auge de expansão a partir de 1950; 
b) a segunda geração, que teve sua maior expressão nas décadas de 1970 e 1980, caracterizou-se pelo uso de mídias de comunicação como rádio, televisão, teleconferências e fitas de áudio e vídeo. Esses materiais didáticos e diferentes tecnologias trouxeram maior interatividade e flexibilidade para o ensino e aprendizagem nessa modalidade;

c) já a terceira geração de EaD no Brasil vem se consolidando desde 1990, e tem como prioridade a interação e colaboração entre os sujeitos do processo de ensino e aprendizagem e a qualidade na comunicação. Essa geração marca o uso de tecnologias como: computadores, Internet, videoconferência e os ambientes virtuais de aprendizagem, abrangendo grande parte dos tipos de materiais didáticos dos modelos de EaD da atualidade;

d) segundo os autores, em fase experimental emergem no cenário mundial atual, a quarta e quinta gerações, caracterizadas pelo uso da inteligência artificial e realidade virtual. Na quarta geração os alunos interagem diretamente com a máquina que gerencia a aprendizagem. Já na quinta geração, a aprendizagem se dá por meio da imersão em ambientes três dimensões (3D) de realidade virtual.

Assim, o desenvolvimento das tecnologias da informação e comunicação abriu portas para novas formas de veiculação dos conteúdos, provocando grandes mudanças nos métodos de produção dos materiais didáticos. No entanto, a produção e revisão de materiais para a educação a distância assume características diferenciadas das de produção e revisão para a educação presencial. Principalmente devido às concepções e particularidades nas dinâmicas destas diferentes modalidades.

No sistema presencial, a interação acontece de forma direta, o professor pode aplicar alterações nos procedimentos avaliativos, ajustar os materiais didáticos, adaptar estratégias de ensino, entre outros, assim que perceber a necessidade, pois tem a possibilidade de interagir diretamente com seus alunos e, a partir dessa interação, identificar, analisar e proceder com as alterações que julgar necessárias. Dessa forma, o retorno para potencializar o ensino e a aprendizagem pode ser imediato.

Já no sistema de educação a distância, basicamente esse retorno não acontece de forma imediata, porque as interações acontecem por meio da mediação das tecnologias. Em EaD, o material didático prevê, além de todo conteúdo científico necessário, grande parte das estratégias didático-pedagógicas antecipadamente. Assim, ajustes de conteúdo, de estratégias didáticas, de comunicação, de formato (caso sejam necessários), só serão detectados e efetivados após a mobilização de um grupo de agentes, que por meio de diferentes processos, mobilizam-se para avaliar, analisar e aplicar estes ajustes e atualizações nos materiais.

Quando se trata da modalidade a distância é necessário ater-se ao fato de que o material didático produzido para essa modalidade deve mediar a relação do aluno com sua aprendizagem. Nesse contexto, Martins e Oliveira $(2008, p .8)$ afirmam que o material deve ser a "voz do professor" perante os alunos. 
Independentemente da mídia utilizada, o material didático é um recurso de comunicação pedagógica. Para que a comunicação aconteça, é necessário que o código utilizado seja comum tanto para o locutor quanto para o interlocutor, coincidindo e propiciando ampliar a interpretação de um com o significado dado pelo outro.

Os materiais didáticos na EaD podem ser disponibilizados de diversas formas e formatos, de acordo com os recursos disponíveis, a necessidade dos conteúdos e os objetivos de aprendizagem que se espera alcançar. A diversificação de mídias educacionais para a EaD, nesse sentido, é de fundamental importância.

\subsubsection{Mídias educacionais diversificadas}

A educação depende diretamente da comunicação, é um processo comunicacional em que alunos e professores estabelecem uma relação educativa dialógica e plural. (PORTO, 2006).

Assim, ao pensar no projeto de um curso e em situações de ensino que visam a aprendizagem, é necessário refletir: "sobre qual estrutura comunicacional será construída essa relação educacional?"

Sendo assim, em todos os modelos de educação deve existir comunicação entre os agentes do processo de ensino e aprendizagem.

$\mathrm{Na}$ EaD essa comunicação ocorre por intermédio de alguma forma de tecnologia, que pode incluir desde mídias gravadas até mídias interativas. Nesse sentido, podem ser desenvolvidos diferentes projetos de educação a distância baseados em diversificados suportes, como o telefone, o rádio, a televisão, o computador e a Internet. As tecnologias mais utilizadas são os materiais didáticos impressos, CDs, CD-ROMs, softwares, Internet, e-mail, teleconferências, videoconferências, espaços virtuais de aprendizagem, entre outros.

Contudo, é importante observar que existem princípios básicos para o uso dessas diferentes tecnologias aplicáveis à educação, um dos quais consiste em "reconhecer que nenhuma tecnologia, isoladamente, é a melhor para a veiculação de todo tipo de mensagem a todos os alunos, em todos os lugares". (MOORE; KEARSLEY, 2007, p. 16).

Partindo deste, temos outro princípio que diz respeito à importância de os projetos de EaD utilizarem pelo menos uma tecnologia gravada, adequada, principalmente, para a transmissão de conteúdo; e outra relacionada à interação entre os agentes do processo de ensino e aprendizagem, pois torna-se fundamental considerar as potencialidades e limitações de cada uma das mídias.

Assim, a integração dos materiais didáticos (impressos, audiovisuais e material para ambiente virtual de aprendizagem) torna-se fundamental, não só com o intuito de que 
eles se complementem, mas que o material produzido possa apresentar, inclusive, certo grau de redundância, aproveitando para explorar a potencialidade das diversas mídias e apresentar os conteúdos em diferentes formatos.(BRASIL, 2007b).

Nesse sentido, a escolha e utilização de determinadas mídias fica condicionada às diferentes concepções e práticas pedagógicas dos cursos, aos conteúdos, às estratégias de ensino, aos contextos socioeconômicos e culturais do público-alvo (alunos) e à infraestrutura tecnológica disponível nas instituições.

Ainda segundo os Referenciais pra Elaboração de Materiais Didáticos:

Uma vez identificadas as possibilidades objetivas de acesso às diferentes mídias, é importante que o projeto pedagógico preveja a utilização do maior número possível de meios, de modo a permitir o atendimento aos diferentes estilos de aprendizagem de seus alunos. (BRASIL, 2007b, p.5).

Dessa forma, a diversificação de mídias é um importante aspecto de qualificação do ensino em EaD, pois oportuniza diferentes formas de disponibilização dos conteúdos por meio dos materiais didáticos, além de ampliar os caminhos de interação entre alunos e professor. Assim, em qualquer situação de ensino, tanto na modalidade presencial como na modalidade a distância, a exploração de diferentes linguagens potencializa as experiências de aprendizagem, tornando-as prazerosas, produtivas e mais significativas.

\subsubsection{Material impresso e ambiente on-line}

Atualmente, os principais meios de disponibilização de conteúdos na EaD são os materiais didáticos impressos e os ambientes on-line de aprendizagem ou Espaços Virtuais de Aprendizagem (EVA), também denominados Ambientes Virtuais de Aprendizagem (AVA).

Na modalidade a distância, os materiais didáticos impressos são os principais meios de socialização do conhecimento e de orientação do processo de aprendizagem, articulados com outras mídias: vídeo, videoconferência, telefone, CDs, DVDs, fax e ambiente virtual. (BRASIL, 2007b, p.6).

Estudar utilizando material impresso é vantajoso por ser de fácil utilização e de fácil transporte, por permitir que se façam anotações e, ainda, por apresentar a mobilidade de ser lido em diversos lugares, a qualquer tempo, respeitando o ritmo da aprendizagem do aluno.

Diante disso, os materiais didáticos impressos permitem a flexibilidade e a autonomia no horário de estudo, onde é respeitado o ritmo de aprendizagem individual, apresentando a possibilidade de consulta, estudo e revisão. Contudo, cada mídia possui suas limitações e, nesse sentido, é preciso que ao tratar de projetos de cursos para a EaD tenha-se à disposição pelo menos duas mídias para veiculação dos conteúdos e interação. 
Com a utilização do computador como ferramenta de ensino abriu-se a possibilidade de criação de materiais didáticos que agregam várias mídias, proporcionando a ampliação de conhecimento de forma interativa, complementar e hipertextual. (BRASIL, 2007b, p.7).

A Internet possibilitou a formação de um ambiente virtual de ensino e aprendizagem, permitindo a integração dos conteúdos disponíveis em outras mídias, além de disponibilizara interatividade, a formação de grupos de estudo, a produção colaborativa e a comunicação entre professor e alunos, e desses entre si.

Essas condições e recursos levaram a produção de material didático a maximizar a autonomia e a interação do aluno no processo de aprendizagem. Nos ambientes on-line, por exemplo, os alunos têm à disposição o conteúdo da disciplina em outros formatos (pdfs, docs), além de poder aprender por meio de web aulas, objetos de aprendizagem interativos, web conferências, chats entre outros.

Portanto, cada mídia tem sua especificidade e pode contribuir para se atingir determinados níveis de aprendizagem, com maior, ou menor grau de facilidade. Nesse sentido, cada mídia tem vantagens e limitações. Assim, os responsáveis pela elaboração dos materiais didáticos precisam ter claro quais são as possibilidades apresentadas pelas diversas mídias, para que todos os envolvidos no processo de elaboração - como, por exemplo, professores, designers educacionais, juntamente com equipes técnicas e gestores envolvidos no planejamento e implementação de cursos em EaD - possam definir quais meios são mais apropriados para veicular determinado conteúdo.

\subsection{Avaliação do material didático}

O material didático, tanto com relação à abordagem do conteúdo quanto à sua forma, deve ser estruturado de acordo com os princípios epistemológicos, metodológicos e políticos explicitados no projeto pedagógico da instituição e curso ao qual pertence, de modo a promover a construção do conhecimento e mediar a interlocução entre estudante e professor. Por esse motivo, a avaliação é essencial, pois conforme Bittencourt (2010, p.91):

A avaliação é um elemento substancial do processo de ensino-aprendizagem de um projeto de EaD. É ela que certifica a sua seriedade e estabelece a credibilidade. A avaliação é necessária para não se perderem os parâmetros de aprendizagem, os objetivos de ensino e a sustentabilidade do projeto.

O material didático em EaD é o principal elemento de viabilidade do projeto e desenho pedagógico de um curso. Para tanto, avaliá-lo em suas diversas dimensões (técnica, estética, didática e comunicacional) torna-se fundamental, pois os resultados desse olhar sobre os materiais proporcionarão repensar e revisar desde pequenos detalhes até a concepção e a própria estrutura desses materiais, caso seja necessário. Conforme afirma Bittencourt (2010, p. 94): 
A avaliação desempenha um papel de suma importância como instrumento sistemático de correções de falhas e promoção de acertos. Por isso, ela não pode ser realizada isoladamente do processo de execução e acompanhamento das ações. Devidamente planejada, torna-se tarefa e competência de todos os envolvidos no processo.

Vê-se que, a avaliação do material didático é um processo que deve acontecer durante e após o processo de produção e abrange a participação de todos os envolvidos no processo, desde os professores, alunos, tutores, designers educacionais, coordenações, monitores, entre outros. Assim, os resultados desta avaliação, conforme Sartori e Roesler (2005) subsidiarão o repensar sobre a concepção do material, revisando a estrutura, a linguagem, a escolha dos conteúdos, os tipos de atividades propostas, as mídias utilizadas e o tempo exigido para estudo.

Desse modo, a avaliação é uma importante estratégia de revisão do material e de todo o processo de ensino. De acordo com Neves (2003, p. 9) "cursos e programas a distância, pelo seu caráter diferenciado e pelos desafios que enfrentam, devem ser acompanhados e avaliados em todos os seus aspectos, de forma sistemática, contínua e abrangente."

Portanto, o material didático desenvolvido para cursos a distância não deve ser engessado. Ao contrário, deve ser encarado como passível de ser revisado, ampliado, modificado, reformulado e adaptado conforme as necessidades encontradas ao longo da elaboração e posterior implementação e desenvolvimento do curso.

\section{CONCLUSÃO}

Foi possível constatar que as orientações contidas nos documentos Referenciais de Qualidade para Cursos a Distância e nos Referenciais para Elaboração de Materiais Didáticos para a EaD no Ensino Profissional e Tecnológico surgem de uma justificada preocupação com relação ao crescente número de cursos ofertados na modalidade a distância. É com a intenção de garantir a qualidade dos processos e nortear o desenvolvimento e a manutenção da $\mathrm{EaD}$, que estes referenciais são lançados, podendo servir como importantes orientadores preliminares para o desenvolvimento e implementação de cursos.

Partindo da análise teórica desenvolvida, foi possível perceber que os materiais didáticos são recursos que merecem uma atenção especial quando se trata de educação a distância, pois nessa modalidade, os materiais didáticos, em seus mais variados formatos, são responsáveis pela organização, desenvolvimento e dinâmica de todo o processo educativo. Para tal, os materiais didáticos devem ser planejados, desenvolvidos e aplicados respeitando as características e especificidades que a modalidade exige.

Diante do exposto, pode-se concluir que a importância de lançar o olhar sobre os materiais didáticos e enfatizar sua avaliação está, em grande parte, na garantia da manutenção dos níveis de qualidade que se requer e se espera do ensino e aprendizagem para a educação a distância. 


\title{
EDUCATIONAL RESOURCE MATERIALS AS FUNDAMENTAL TOOLS IN POTENCIALIZAÇÃO OF QUALITY TEACHING IN EAD
}

\begin{abstract}
The purpose of this article is to demonstrate, through analysis of theoretical references on the subject, the importance of teaching materials for the improvement of teaching and learning in Distance Education (DE). As a result, it was found that the materials prepared for courses in this modality need to be developed according to the concept of Distance Education of the institution and must be constantly evaluated, revised and updated in line with advances and discoveries in the field of knowledge that they cover, enabling a teaching and learning of quality. Hence we understand that, in Distance Education, the teaching material is fundamental, since involves the organization, the development and dynamics of the whole process of teaching and learning, in addition to providing much of the didactic and pedagogical strategies.
\end{abstract}

Keywords: Distance. Courseware. Teaching and learning. 


\section{REFERÊNCIAS}

BITTENCOURT, Dênia Falcão de. As métricas, o projeto e o design na EaD. In: Material didático on-line da disciplina design e projetos em educação a distância do curso de especialização em metodologia da educação a distância. Florianópolis: UnisulVirtual, 2010.

BRASIL. Ministério da Educação. Lei no. 9.394/96, de 20 de dezembro de 1996. Lei de Diretrizes e Bases da Educação Nacional. Disponível em: <http://www.planalto.gov.br/ ccivil_03/Leis/L9394.htm>. Acesso em: 27 jul. 2010.

Ministério da Educação. Secretaria de Educação a Distância. Referenciais de qualidade para a educação superior a distância. Brasília, 2007a. Disponível em: $<$ http://portal.mec.gov.br/seed/arquivos/pdf/legislacao/refead1.pdf>. Acesso em: 05 ago. 2012.

. Ministério da Educação. Secretaria de Educação a Distância. Referenciais de qualidade para cursos a distância. Brasília, 2003. Disponível em: <http://portal.mec. gov.br/seed/arquivos/pdf/ReferenciaisdeEAD.pdf>. Acesso em: 13 set. 2012.

Ministério da Educação. Secretaria de Educação a Distância. Referenciais para elaboração de materiais didáticos para a EaD no ensino profissional e tecnológico. Brasília, 2007b. Disponível em: <www.etecbrasil.mec.gov.br/gCon/recursos/upload/.../ ref_materialdidatico.pdf>. Acesso em: 13 set. 2012.

KENSKI, Vani M. Tecnologias e ensino presencial a distância. 7. ed. Campinas, SP: Papirus, 2009.

MARTINS, Jana Gonçalves; OLIVEIRA, Nadia Fátima de. Material didático: desconstruindo o ontem para construir o hoje e o amanhã. [S.I: s.n.], 2008. Disponível em: <http://www.abed.org.br/congresso2008/tc/512200834611PM.pdf>. Acesso em: 30 ago. 2012.

MOORE, Michael G.; KEARSLEY, Greg. Educação a distância: uma visão integrada - Edição especial ABED - Associação Brasileira de Educação a Distância. São Paulo:Thomson Learning, 2007. 
NEVES, Carmen Moreira de Castro. Indicadores de qualidade para cursos a distância. Brasília, 2003. Disponível em: <http://www.pr5.ufrj.br/curso_distancia/legislacao/ Indicadores_de_Qualidade_do_MEC.pdf>. Acesso em: 27 jul. 2012.

PORTO, Tânia Maria Esperon. As tecnologias de comunicação e informação na escola: relações possíveis...relações construídas. Rev. Bras. de Edu [online], v. 11, n.31, p.4357, jan./abr. 2006. Disponível em: <http://www.scielo.br/scielo.php?script=sci_arttext\& pid=S1413-24782006000100005>. Acesso em: 09 ago. 2012.

SARTORI, Ademilde Silveira; ROESLER, Jucimara. Educação superior a distância: gestão da aprendizagem e da produção de materiais didáticos impressos e on-line. Tubarão: Unisul, 2005.

TORRES, Patrícia Lupion; FIALHO, Francisco Antônio Pereira. Educação a distância: passado, presente e futuro. In: LITTO, Fredric M.; FORMIGA, Manuel Marcos Maciel (Orgs.). Educação a Distância: o estado da arte. São Paulo: Pearson Education do Brasil, 2009.

WISSMANN, Liane Dal Molin. Autonomia em EaD - uma construção coletiva. In: POMMER, Arnildo; SILVA, Enio Waldir da et al. Educação superior na modalidade a distância: construindo novas relações professor-aluno. Série Textos Didáticos. Ijuí/RS: Editora Unijuí, 2006. Disponível em: <http://www2.unijui.edu.br/ liaw/Autonomia\%20 em\%20EaD\%20.pdf>. Acesso em: 06 set. 2012. 


\section{SOBRE A AUTORA}

\begin{tabular}{|c|l||}
\hline $\begin{array}{l}\text { Pedagoga pela Universidade Federal de Santa Catarina (UFSC). É especialista } \\
\text { em Ciências da Educação pela Universidade do Sul de Santa Catarina } \\
\text { (UNISUL) e Universitá Ca' Foscari di Venezia (Itália). Trabalhou no setor de } \\
\text { Desenho e Desenvolvimento de Materiais Didáticos da UnisulVirtual no } \\
\text { desenvolvimento, revisão e atualização de materiais didáticos impressos e } \\
\text { espaço virtual de aprendizagem para cursos de graduação, pós-graduação } \\
\text { e extensão a distância. Atuou como tutora na Universidade Aberta do } \\
\text { Brasil (UAB). Atualmente é Designer Educacional, trabalha no setor de } \\
\text { Desenvolvimento de Recursos Didáticos (DRD) do SENAI/SC, atuando } \\
\text { no desenvolvimento de projetos educacionais, design e roteirização de } \\
\text { materiais impressos, objetos de aprendizagem e ambientes on-line. }\end{array}$ \\
Corrêa
\end{tabular}

